Pacific Journal of Mathematics

ON QUASI-COMPLEMENTS 


\title{
ON QUASI-COMPLEMENTS
}

\author{
WiLliaM B. JOHNSON
}

\begin{abstract}
Results of $\mathbf{H}$. P. Rosenthal and the author on $w^{*}$-basic sequences are combined with known techniques and applied to quasi-complementation problems in Banach spaces.
\end{abstract}

1. Introduction. Recall that (closed, linear) subspaces $Y, Z$ of the Banach space $X$ are quasi-complements (respectively complements) provided $Y \cap Z=\{0\}$ and $Y+Z$ is dense in $X$ (respectively, $Y+$ $Z=X)$.

Suppose that $Y, Z$ are quasi-complements, but not complements, for the separable space $X$. We show that there exist closed subspaces $Y_{1}$ and $Y_{2}$ of $X$ with $Y_{1} \subset Y \subset Y_{2}, \operatorname{dim} Y / Y_{1}=\infty=\operatorname{dim} Y_{2} / Y$, such that $Y_{1}, Z$ are quasi-complements and $Y_{2}, Z$ are quasi-complements. This generalizes a theorem of James [5], who proved the existence of $Y_{1}$ for the case of general separable $X$ and the existence of $Y_{2}$ for separable, reflexive $X$. Our proof uses James' method (and $w^{*}$ basic sequences), but seems simpler than James' construction. Also, our argument provides information for some nonseparable spaces.

We show also the following.

Theorem 2. Suppose $Y$ is a subspace of $X$ and $Y^{*}$ is weak*separable. If $X / Y$ has a separable, infinite dimensional quotient space, then $Y$ is quasi-complemented in $X$.

Theorem 2 was discovered by J. Lindenstrauss and H. P. Rosenthal [unpublished], both of whom apparently use an idea from [3]. Our argument uses $w^{*}$-basic sequences and Rosenthal's proof of Theorem 2 in the case where $X / Y$ has a reflexive, infinite dimensional quotient (cf. [12]).

The final result of the paper is that every subspace of a separable conjugate space admits a weak*-closed quasi-complement which is spanned by a boundedly complete $w^{*}$-basic sequence.

The notation and terminology agree with [6]. In particular, subspaces and quotients are assumed to be infinite dimensional and complete. For $A \subset X, A^{\perp}$ is the annihilator of $A$ in $X^{*}$, while for $B \subset X^{*}, B^{\tau}$ is the annihilator of $B$ in $X$ and $\widetilde{B}$ is the weak*-closure of $B$ in $X^{*}$.

II. The Theorems. We recall the definition of $w^{*}$-basic sequence 
[6]: A sequence $\left(y_{n}\right) \subset X^{*}$ is called $w^{*}$-basic provided that there exists $\left(x_{n}\right) \subset X$ biorthogonal to $\left(y_{n}\right)$ and, for each $y$ in the weak ${ }^{*}$-closure $\left[\widetilde{y}_{n}\right]$ of the closed linear $\operatorname{span}\left[y_{n}\right]$ of $\left(y_{n}\right), y=w^{*}-\lim _{n} \sum_{i=1}^{n} y\left(x_{i}\right) y_{i}$.

In [6] it was proved that, when $X$ is separable, if $\left(y_{n}\right) \subset X^{*}$, $y_{n} \stackrel{w^{*}}{\longrightarrow} 0$, but $\lim \inf \left\|y_{n}\right\|>0$, then $\left(y_{n}\right)$ contains a $w^{*}$-basic subsequence. Let us note that the same result is true when $X$ admits a weakly compact fundamental set. Indeed, in this case there exists by [1] a norm one projection $P$ on $X$ with $P X$ separable and $\left(y_{n}\right) \subset P^{*} X^{*}$. $P^{*} X^{*}$ is isometric to $(P X)^{*}$ and the relative weak ${ }^{*}$ topology on $P^{*} X^{*}$ from $X^{*}$ agrees with the weak ${ }^{*}$ topology on $P^{*} X^{*}$ considered as the conjugate of $P X$. Therefore, the above mentioned result from [6] applies to show that $\left(y_{n}\right)$ has a $w^{*}$-basic subsequence.

First we prove the extension of James' theorem:

THEOREM 1. Suppose that $Y, Z$ are quasi-complements, but not complements, for $X$.

(a) If $Y$ has a weakly compact fundamental subset, then there exists a subspace $Y_{1}$ of $Y$ with $\operatorname{dim} Y / Y_{1}=\infty$ and $Y_{1}, Z$ are quasicomplements.

(b) If $X / Y$ has a weakly compact fundamental subset (in particular, if $X$ does), then there exists a subspace $Y_{2}$ of $X$ with $Y_{2} \supset Y$, $\operatorname{dim} Y_{2} / Y=\infty$, and $Y_{2}, Z$ are quasi-complements.

Proof. Pick positive numbers $\left(a_{n}\right)$ less than 1 so that $a_{1}+a_{1} a_{2}+$ $a_{1} a_{2} a_{3}+\cdots<\infty$. Let $p$ be a bijection of $N \times N$ onto $N$ ( $N$ is the set of natural numbers) so that for each $n$ and $j, p(n, j) \geqq j$.

To prove (a), we use the fact that $Y+Z$ is not closed to select unit vectors $\left(y_{n}\right)$ in $Y$ with $d\left(y_{n}, Z\right) \equiv \inf \left\{\left\|y_{n}+z\right\|: z \in Z\right\} \rightarrow 0$. Since $Y \cap Z=\{0\}, 0$ is the only possible weak cluster point of $\left(y_{n}\right)$, and hence either $y_{n} \stackrel{w}{\longrightarrow} 0$ or the weak closure of $\left(y_{n}\right)$ is not weakly compact. Thus, by either [2] or [11], $\left(y_{n}\right)$ has a basic subsequence, which we also denote by $\left(y_{n}\right)$.

Let $\left(y_{n}^{*}\right)$ be a bounded sequence of functionals in $Y^{*}$ biorthogonal to $\left(y_{n}\right)$. Since $Y$ admits a weakly compact fundamental set, the unit ball of $Y^{*}$ is weak* sequentially compact (cf. [1]), so we may assume, by passing to a subsequence, that $y_{n}^{*} \stackrel{w^{*}}{\longrightarrow} y^{*} .\left(y_{n}^{*}-y^{*}\right)$ converges $w^{*}$ to 0 and is bounded away from zero, so it has a $w^{*}$-basic subsequence. Thus by passing to a subsequence of $\left(y_{n}, y_{n}^{*}-y^{*}\right)$, we have that there exists a biorthogonal sequence $\left(x_{n}, x_{n}^{*}\right)$ in $Y$ with $\left\|x_{n}\right\|=1,\left(\left\|x_{n}^{*}\right\|\right)$ bounded, $d\left(x_{n}, Z\right) \leqq n^{-1} a_{1} a_{2} a_{3} \cdots a_{n},\left(x_{n}\right)$ is basic, and $\left(x_{n}^{*}\right)$ is $w^{*}$-basic. 
Let $Y_{1}=\left[\left(x_{i}^{*}\right)^{\tau} \cup\left(a_{i} x_{p(n, i)}-x_{p(n, i+1)}\right)_{i, n=1}^{\infty}\right]$. (The annihilator of $\left(x_{i}^{*}\right)$ is of course taken in $Y$.) We claim that $Y_{1} \cap\left[x_{p(n, 1)}\right]=\{0\}$. To see this, first note that $w_{n}^{*}=x_{p(n, 1)}^{*}+a_{1} x_{p(n, 2)}^{*}+a_{1} a_{2} x_{p(n, 3)}^{*}+\cdots$ is absolutely convergent, $w_{n}^{*}\left(x_{p(n, 1)}\right)=1$, while $w_{n}^{*}\left(x_{p(m, 1)}\right)=0$ when $n \neq m$. By construction, $Y_{1} \subset\left(w_{n}^{*}\right)^{\tau}$, and $\left(w_{n}^{*}\right)^{\tau} \cap\left[\left(x_{p(n, 1)}\right)\right]=\{0\}$ because $\left(x_{p(n, 1)}\right)$ is basic under some ordering and $\left(x_{p(n, 1)}, w_{n}^{*}\right)$ is biorthogonal. Hence, $Y_{1} \cap\left[x_{p(n, 1)}\right]=\{0\}$, whence $\operatorname{dim} Y / Y_{1}=\infty$.

We complete the proof by showing that $Y_{1}+Z$ is dense in $X$. Now $\left(x_{n}^{*}\right)^{\tau}+\left[x_{n}\right]$ is dense in $Y$ because $\left(x_{n}^{*}\right)$ is $w^{*}$-basic, so we need show only that $\left(x_{p(n, 1)}\right) \subset \overline{Y_{1}+Z}$. But

$$
\begin{aligned}
x_{p(n, 1)} & -a_{1}^{-1}\left(a_{1} x_{p(n, 1)}-x_{p(n, 2)}\right)-\left(a_{1} a_{2}\right)^{-1}\left(a_{2} x_{p(n, 2)}-x_{p(n, 3)}\right) \\
& -\cdots-\left(a_{1} a_{2} \cdots a_{j}\right)^{-1}\left(a_{j} x_{p(n, j)}-x_{p(n, j+1)}\right) \\
= & \left(a_{1} a_{2} \cdots a_{j}\right)^{-1} x_{p(n, j+1)} .
\end{aligned}
$$

Since $d\left(x_{p(n, j+1)}, Z\right) \leqq p(n, j+1)^{-1} a_{1} a_{2} \cdots a_{p(n, j+1)} \leqq(j+1)^{-1} a_{1} a_{2} \cdots a_{j}$, it follows that $d\left(x_{p(n, 1)}, Y_{1}+Z\right) \leqq(j+1)^{-1}$. Since $j$ is arbitrary, this completes the proof of (a).

The proof of (b) is very similar to the above: Since $Y, Z$ are not complements, $Y^{\perp}+Z^{\perp}$ is not closed in $X^{*}$. Thus there exists a sequence $\left(y_{n}^{*}\right)$ of unit vectors in $Y^{\perp}$ with $d\left(y_{n}^{*}, Z^{\perp}\right) \rightarrow 0$. Of necessity, $y_{n}^{*} \stackrel{w^{*}}{\longrightarrow} 0$. Now $Y^{\perp}=(X / Y)^{*}$ in the canonical way, so $\left(y_{n}^{*}\right)$ has a $w^{*}$-basic subsequence. Hence for an appropriate subsequence $\left(x_{n}^{*}\right)$ of $\left(y_{n}^{*}\right)$, we have that there exists a biorthogonal sequence $\left(x_{n}, x_{n}^{*}\right)$ in $X$ with $\left(\left\|x_{n}\right\|\right)$ bounded, $\left\|x_{n}^{*}\right\|=1,\left(x_{n}^{*}\right) \subset Y^{\perp},\left(x_{n}^{*}\right) w^{*}$-basic, and $d\left(x_{n}^{*}, Z^{\perp}\right) \leqq$ $n^{-1} a_{1} a_{2} \cdots a_{n}$.

We define $Y_{2}^{\perp}$ to be the weak*-closure of $\left[Y^{\perp} \cap\left(x_{n}\right)^{\perp} \cup\left(a_{i} x_{p(n, i)}^{*}-\right.\right.$ $\left.\left.x_{p(n, i+1)}^{*}\right)_{n, i=1}^{\infty}\right]$. Since $Y_{2}^{\perp} \subset Y^{\perp}$, we have $Y_{2} \supset Y$. To show that $\operatorname{dim} Y_{2} /$ $Y=\infty$, it clearly suffices to prove that $Y_{2}^{\perp} \cap \overline{\left[x_{p(n, 1)}^{*}\right]}=\{0\}$. But note that $y_{n} \equiv x_{p(n, 1)}+a_{1} a_{2} x_{p(n, 2)}+a_{1} a_{2} a_{3} x_{p(n, 3)}+\cdots$ is absolutely convergent, $x_{p(n, 1)}^{*}\left(y_{n}\right)=1$, while $x_{p(m, 1)}^{*}\left(y_{n}\right)=0$ when $m \neq n$. By construction, $\left(y_{n}\right)^{\perp} \supset\left(a_{i} x_{p(n, i)}^{*}-x_{p(n, i+1)}^{*}\right)_{n, i=1}^{\infty}$ and $\left(y_{n}\right)^{\perp} \supset\left(x_{n}\right)^{\perp}$, hence $\left(y_{n}\right)^{\perp} \supset Y_{2}^{\perp}$. But $\left(y_{n}\right)^{\perp} \cap\left[\widehat{\left.x_{p(n, 1)}^{*}\right]}=\{0\}\right.$ because $\left(x_{p(n, 1)}^{*}\right)$ is $w^{*}$-basic in some ordering and $\left(y_{n}, x_{p(n, 1)}^{*}\right)$ is biorthogonal.

Since $Y_{2}^{\perp} \cap Z^{\perp} \subset Y^{\perp} \cap Z^{\perp}=\{0\}$, we have that $Y_{2}+Z$ is dense in $X$. To show that $Y_{2} \cap Z=\{0\}$, we prove the equivalent fact that $Y_{2}^{\perp}+Z^{\perp}$ is $w^{*}$ dense in $X^{*}$. But $Y^{\perp} \cap\left(x_{n}\right)^{\perp}+\left[x_{n}^{*}\right]$ is $w^{*}$ dense in $Y^{\perp}$ because $\left(x_{n}^{*}\right)$ is $w^{*}$-basic, so we need only show that each $x_{p(n, 1)}^{*}$ is in the closure of $Y_{2}^{\perp}+Z$. To see that this last statement is true, write 


$$
\begin{aligned}
x_{p(n, 1)}^{*} & -a_{1}^{-1}\left[a_{1} x_{p(n, 1)}^{*}-x_{p(n, 2)}^{*}\right]-\left(a_{1} a_{2}\right)^{-1}\left[a_{2} x_{p(n, 2)}^{*}-x_{p(n, 3)}^{*}\right]-\cdots \\
& -\left(a_{1} a_{2} \cdots a_{j}\right)^{-1}\left[a_{j} x_{p(n, j)}^{*}-x_{p(n, j+1)}^{*}\right] \\
= & \left(a_{1} a_{2} \cdots a_{j}\right)^{-1} x_{p(n, j+1)}^{*} \cdot
\end{aligned}
$$

Since $d\left(x_{p(n, j+1)}^{*}, Z\right) \leqq p(n, j+1)^{-1} a_{1} a_{2} \cdots a_{p(n, j+1)} \leqq(j+1)^{-1} a_{1} \cdots a_{j}$, we have $d\left(x_{p(n, 1)}^{*}, Y_{2}^{\perp}+Z\right) \leqq(j+1)^{-1}$ for arbitrary $j$.

Next we prove the result of Lindenstrauss and Rosenthal.

Proof of Theorem 2. Since $X / Y$ has a separable quotient, there exists a biorthogonal sequence $\left(x_{n}, x_{n}^{*}\right)$ in $X$ with $\left(x_{n}^{*}\right) \subset Y^{\perp},\left(x_{n}^{*}\right) w^{*}$ basic, and normalized so that $\left\|x_{n}\right\|=1$. Since $Y^{*}$ is $w^{*}$-separable, a biorthogonalization argument (cf., e.g., [8] or [7]) shows that there exists a biorthogonal sequence $\left(y_{n}, y_{n}^{*}\right)$ for $Y$ with $\left(y_{n}^{*}\right) \subset X^{*}, Y \cap\left(y_{n}^{*}\right)^{\tau}=$ $\{0\}$, and normalized so that $\left\|y_{n}^{*}\right\|=1$.

Define $T: X \rightarrow X$ by $T x=\sum_{n=1}^{\infty} 2^{-n-1} y_{n}^{*}(x) x_{n}$. Then $\|T\| \leqq 1 / 2$, so $I+T$ is an isomorphism. Hence $(I+T)^{*}$ is a weak*-isomorphism on $X^{*}$, whence $\left(x_{n}^{*}+T^{*} x_{n}^{*}\right)$ is a $w^{*}$-basic sequence $w^{*}$-equivalent to $\left(x_{n}^{*}\right)$.

Computing $T^{*} x_{n}^{*}$, we have $T^{*} x_{n}^{*}(x)=x_{n}^{*} T x=x_{n}^{*} \sum_{m=1}^{\infty} 2^{-m-1} y_{m}^{*}(x) x_{m}=$ $2^{-n-1} y_{n}^{*}(x)$; i.e., $T^{*} x_{n}^{*}=2^{-n-1} y_{n}^{*}$.

We claim that $\left(x_{n}^{*}+2^{-n-1} y_{n}^{*}\right)^{\tau}$ is a quasi-complement to $Y$. First we show that $Y^{\perp} \cap \overline{\left[x_{n}^{*}+2^{-n-1} y_{n}^{*}\right]}=\{0\}$ (so that $Y+\left(x_{n}^{*}+2^{-n-1} y_{n}^{*}\right)^{\tau}$ is dense). But if $\left.x^{*} \in \overline{\left[x_{n}^{*}+2^{-n-1} y_{n}^{*}\right.}\right]$, then, since $\left(x_{n}^{*}+2^{-n-1} y_{n}^{*}\right)$ is $w^{*}$ equivalent to $\left(x_{n}^{*}\right)$, we can write $x^{*}=w^{*}-\lim _{n \rightarrow \infty} \sum_{i=1}^{n} \alpha_{i} x_{i}^{*}+\sum_{i=1}^{\infty} 2^{-i-1} \alpha_{i} y_{i}^{*}$ for some sequence $\left(\alpha_{i}\right)$ of scalars. Thus for each $n, x^{*}\left(y_{n}\right)=2^{-n-1} \alpha_{n}$, hence, since $x^{*} \in Y^{\perp}, \alpha_{n}=0$.

We complete the proof by showing that $Y \cap\left(x_{n}^{*}+2^{-n-1} y_{n}^{*}\right)^{\tau}=\{0\}$. For suppose $y$ is in this intersection. Since $y \in Y, x_{n}^{*}(y)=0$ for each $n$. Hence $y_{n}^{*}(y)=0$ for each $n$, whence $y \in\left(y_{n}^{*}\right)^{\tau} \cap Y=\{0\}$.

Theorem 3. Suppose $X^{*}$ is separable and $Y$ is a subspace of $X^{*}$ with $\operatorname{dim} X^{*} / Y=\infty$. Then there exists a weak*-closed subspace $Z$ of $X^{*}$ with $Y, Z$ quasi-complements and $Z=\left[z_{n}\right]$ for some boundedly complete, $w^{*}$-basic sequence $\left(z_{n}\right)$.

Proof. Mackey [8] showed that $Y$ has a quasi-complement, say, $W$. Let $\left(w_{n}, w_{n}^{*}\right)$ be a biorthogonal sequence in $W$ with $\left\|w_{n}\right\|=1$ and $\left[w_{n}\right]=W$ (cf. [9]). By Theorem III. 2 of [6], there exists a 
biorthogonal sequence $\left(x_{n}, x_{n}^{*}\right)$ in $X$ with $\left(x_{n}^{*}\right) \subset Y,\left(x_{n}^{*}\right)$ boundedly complete and $w^{*}$-basic, normalized so that $\left\|x_{n}\right\|=1$.

Define $T: X \rightarrow X$ by $T x=\sum_{n=1}^{\infty} 2^{-n-1} w_{n}(x) x_{n}$. Then $\|T\| \leqq 1 / 2$, so $I+T$ is an isomorphism and hence $(I+T)^{*}$ is a weak*-isomorphism. One checks that $T^{*} x_{n}^{*}=2^{-n-1} w_{n}$, so that $\left(x_{n}^{*}+2^{-n-1} w_{n}\right)$ is a $w^{*}$-basic sequence $w^{*}$-equivalent to $\left(x_{n}^{*}\right)$. Letting $Z=\left[x_{n}^{*}+2^{-n-1} w_{n}\right]$, we have by Proposition 1 of [6] that $Z$ is weak*-closed.

Certainly $Z+Y \supset\left(w_{n}\right)$, so $Z+Y \supset Y+W$ and thus is dense. Suppose that $z \in Z \cap Y$. Then $z=\sum_{n=1}^{\infty} \alpha_{n}\left(x_{n}^{*}+2^{-n-1} w_{n}\right)$ for some scalars $\left(\alpha_{n}\right)$ because $\left(x_{n}^{*}+2^{-n-1} w_{n}\right)$ is basic. Hence also $\sum_{n=1}^{\infty} \alpha_{n} x_{n}^{*}$ converges, whence $z-\sum_{n=1}^{\infty} \alpha_{n} x_{n}^{*}=\sum_{n=1}^{\infty} \alpha_{n} 2^{-n-1} w_{n}$ is again in $Y$. Certainly $\sum_{n=1}^{\infty} \alpha_{n} 2^{-n-1} w_{n}$ is also in $W$ so that $\sum_{n=1}^{\infty} \alpha_{n} 2^{-n-1} w_{n}=0$. Thus $\alpha_{n} 2^{-n-1}=$ $w_{n}^{*}\left(\sum_{m=1}^{\infty} \alpha_{m} 2^{-m-1} w_{m}\right)=0$, so that $z=0$.

REMARK. Separability of $X^{*}$ in Theorem 3 is essential to get that $Z$ is weak*-closed. Indeed, regard $m=l_{1}^{*}$. Rosenthal [12] showed that $c_{0}$ is quasi-complemented in $m$. However, if $Z$ is a quasicomplement for $c_{0}$ in $m$, then $Z$ cannot be weak*-closed. For if $Z$ were $w^{*}$-closed, then $m / Z$ would be isomorphic to $\left(Z^{\tau}\right)^{*}$. But $m / Z$ is separable, hence reflexive (cf. [4]). Thus $Z^{\tau}$ would be a reflexive subspace of $l_{1}$, a contradiction (cf., e.g., [10]).

\section{REFERENCES}

1. D. Amir and J. Lindenstrauss, The structure of weakly compact sets in Banach spaces, Ann. Math., (2), 88 (1968), 35-46.

2. C. Bessaga and A. Pelczynski, On bases and unconditional convergence of series in Banach spaces, Bull. Acad. Polon. Sci., 4 (1959), 379-383.

3. W. J. Davis and J. Lindenstrauss, On total non-norming subspaces, Proc. Amer. Math. Soc., 31 (1972), 109-111.

4. A. Grothendieck, Sur les applications lineaires faiblement compactes d'espaces dutype $C(K)$, Canad. J. Math., 5 (1953), 129-173.

5. R. C. James, Quasi-complements, J. Approximation Theory, 6 (1972), 147-160.

6. W. B. Johnson and H. P. Rosenthal, On $w^{*}$-basic sequences and their applications to the study of Banach spaces, Studia Math., 43 (1972), 77-92.

7. V. Klee, On the Borelian and projective types of linear subspaces, Math. Scand., 6 (1958), 189-199.

8. G. Mackey, Note on a theorem of Murray, Bull. Amer. Math. Soc., 52 (1946), 322-325.

9. A. Markuschevich, Sur les bases (au sens large) dans les espaces linéaires, C. R. (Doklady) Acad. Sci. URSS, 41 (1943), 227-229.

10. A. Pelczynski, Projections in certain Banach spaces, Studia Math., 19 (1960), 209-228.

11. $A$ note on the paper of $I$. Singer, 'Basic sequences and reflexivity of Banach spaces', Studia Math., 21 (1962), 371-374.

12. H. P. Rosenthal, On quasi-complemented subspaces of Banach spaces, with an appendix on compactness of operators from $L^{p}(\mu)$ to $L^{r}(v)$, J. Functional Analysis, 4 (1969), 176-214. 
Received May 16, 1972 and in revised form April 10, 1973. The author was supported in part by NSF GP 28719. Most of the research for this paper was done at the University of Houston.

Ohio State University 


\section{PACIFIC JOURNAL OF MATHEMATICS}

\section{EDITORS}

RICHARD ARENS (Managing Editor)

University of California

Los Angeles, California 90024

R. A. Beaumont

University of Washington

Seattle, Washington 98105
J. DUGUNDJI*

Department of Mathematics

University of Southern California

Los Angeles, California 90007

D. Gilbarg and J. Milgram

Stanford University

Stanford, California 94305

\section{ASSOCIATE EDITORS}
E. F. BECKENBACH
B. H. NeumanN
F. WOLF
K. YosHIDA

\section{SUPPORTING INSTITUTIONS}

UNIVERSITY OF BRITISH COLUMBIA
CALIFORNIA INSTITUTE OF TECHNOLOGY
UNIVERSITY OF CALIFORNIA
MONTANA STATE UNIVERSITY
UNIVERSITY OF NEVADA
NEW MEXICO STATE UNIVERSITY
OREGON STATE UNIVERSITY
UNIVERSITY OF OREGON
OSAKA UNIVERSITY

UNIVERSITY OF BRITISH COLUMBIA

UNIVERSITY OF CALIFORNIA

MONTANA STATE UNIVERSITY

UNIVERSITY OF NEVADA

OREGON STATE UNIVERSITY

OSAKA UNIVERSITY
UNIVERSITY OF SOUTHERN CALIFORNIA

STANFORD UNIVERSITY

UNIVERSITY OF TOKYO

UNIVERSITY OF UTAH

WASHINGTON STATE UNIVERSITY

UNIVERSITY OF WASHINGTON

\section{AMERICAN MATHEMATICAL SOCIETY} NAVAL WEAPONS CENTER

* C. R. DePrima California Institute of Technology, Pasadena, CA 91109, will replace J. Dugundji until August 1974. 


\section{Pacific Journal of Mathematics}

\section{Vol. 48, No. $1 \quad$ March, 1973}

Jan Aarts and David John Lutzer, Pseudo-completeness and the product of Baire

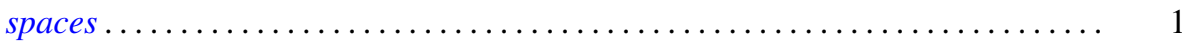

Gordon Owen Berg, Metric characterizations of Euclidean spaces ............ 11

Ajit Kaur Chilana, The space of bounded sequences with the mixed topology ..... . 29

Philip Throop Church and James Timourian, Differentiable open maps of

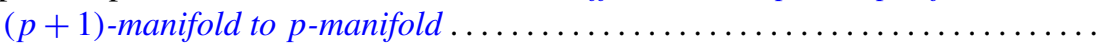

P. D. T. A. Elliott, On additive functions whose limiting distributions possess a finite

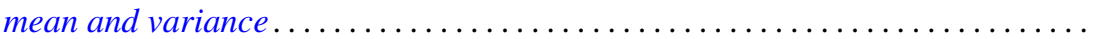

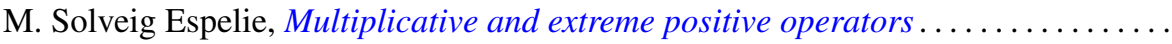

Jacques A. Ferland, Domains of negativity and application to generalized convexity

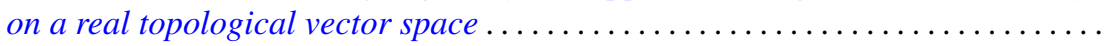

Michael Benton Freeman and Reese Harvey, A compact set that is locally holomorphically convex but not holomorphically convex ...............

Roe William Goodman, Positive-definite distributions and intertwining

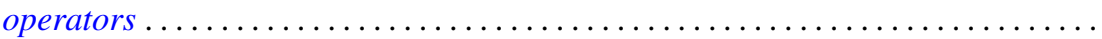

Elliot Charles Gootman, The type of some $C^{*}$ and $W^{*}$-algebras associated with

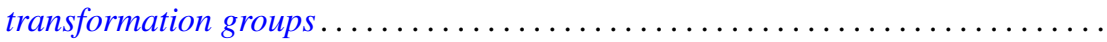

David Charles Haddad, Angular limits of locally finitely valent holomorphic

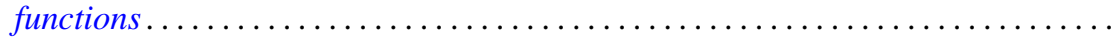

William Buhmann Johnson, On quasi-complements .

William M. Kantor, On 2-transitive collineation groups of finite projective spaces...

Joachim Lambek and Gerhard O. Michler, Completions and classical localizations of right Noetherian rings

Kenneth Lamar Lange, Borel sets of probability measures ......

David Lowell Lovelady, Product integrals for an ordinary differential equation in a Banach space

Jorge Martinez, A hom-functor for lattice-ordered groups .........

W. K. Mason, Weakly almost periodic homeomorphisms of the two sphere ....

Anthony G. Mucci, Limits for martingale-like sequences .......

Eugene Michael Norris, Relationally induced semigroups ...

Arthur E. Olson, A comparison of c-density and $k$-density ......

Donald Steven Passman, On the semisimplicity of group rings of linear groups.

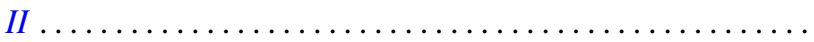

Charles Radin, Ergodicity in von Neumann algebras .

P. Rosenthal, On the singularities of the function generated by the Bergman operator of the second kind.

Arthur Argyle Sagle and J. R. Schumi, Multiplications on homogeneous spaces,

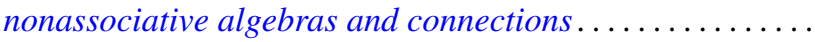

Leo Sario and Cecilia Wang, Existence of Dirichlet finite biharmonic functions on

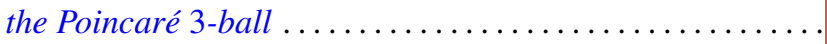

Ramachandran Subramanian, On a generalization of martingales due to Blake ..

Bui An Ton, On strongly nonlinear elliptic variational inequalities.

Seth Warner, A topological characterization of complete, discretely valued

fields. 